\title{
Educação Ambiental: mídia, discursos e o verde
}

\author{
Educación Ambiental: medios, discursos y el verde \\ Environmental Education: media, speeches and the green
}

\author{
Isabel Ribeiro Marques ${ }^{1}$ \\ Paula Correa Henning ${ }^{2}$
}

\begin{abstract}
Resumo
O presente resumo parte de um doutoramento em Educação Ambiental na Universidade Federal de Rio Grande e, através de um recorte de uma tese que analisa a proliferação de discursos relacionados ao "verde" que a escrita é tecida, buscando lançar olhares para a Educação Ambiental através de atravessamentos midiáticos que fazem parte do corpus da tese. O trabalho busca ferramentas teóricas através da Análise do Discurso, inspirando-se em Michel Foucault, operando especificamente com conceito de discurso na busca de tensionamento das condições de possibilidades dos discursos propagados. Com a proposta in situ, compila-se imagens atreladas a temática ambiental e, através desse exercício, questiona-se sobre a expressiva vinculação da área em relação aos recursos naturais, como ar, água, flora, fauna ou então ao verde. E, através de imagens coletadas por diferentes atravessamentos midiáticos, com a experiência docente no ensino superior e em consonância com as pesquisas desenvolvidas, almeja-se criar fissuras de pensamento e reflexão sobre o que vem sendo distribuído em relação a temática ambiental, exercitando um olhar quem sabe mais atento e menos (pré) direcionado.
\end{abstract}

Palavras-Chave: Análise do Discurso; Educação Ambiental; Mídia; Verde.

\section{Resumen}

El presente resumen parte de un doctorado en Educación Ambiental en la Universidad Federal de Rio Grande y, a través de un recorte de una tesis que analiza la proliferación de discursos relacionados al "verde" que la escritura es tejida, buscando arrojar miradas a la Educación Ambiental a través de atravesamientos mediáticos que forman parte de la tesis. El trabajo busca herramientas teóricas a través del análisis del discurso, inspirándose en Michel Foucault, operando específicamente con concepto de discurso en la búsqueda de tensar las condiciones de posibilidades de los discursos propagados. Con la propuesta en situación, se compila imágenes atadas a la temática ambiental y, a través de ese ejercicio, se cuestiona sobre la expresiva vinculación del área en relación a los recursos naturales, como el aire, el agua, la flora, la fauna o el verde. $Y$, a través de imágenes recogidas por diferentes atravesamientos mediáticos, con la experiencia docente en la enseñanza superior y en consonancia con las investigaciones desarrolladas, se anhela crear fisuras de pensamiento y reflexión sobre lo que viene siendo distribuido en relación a la temática ambiental, ejercitando una mirada que sabe más atento y menos direccionado a la temática.

Palabras claves: Análisis del Discurso; Educación Ambiental; Medios; Verde.

\section{Abstract}

The present abstract is based on doctorate in Environmental Education at the Federal University of Rio Grande and, through a clipping of a thesis that analyzes the proliferation of discourses related to the "green" that the

\footnotetext{
${ }^{1}$ Doutoranda em Educação Ambiental na Universidade Federal do Rio Grande - FURG. Mestre em Educação e Tecnologia - IF Sul, Integrante do Grupo de Pesquisa Educação, Cultura, Ambiente e Filosofia GEECAF/FURG. Rio Grande, Rio Grande do Sul, Brasil. - RS Bolsista Capes. isabel.marques.82@gmail.com. Trabalho apresentado no III Encontro Humanístico Multidisciplinar e II Congresso Latino-Americano de Estudos Humanísticos Multidisciplinares, Jaguarão/RS, Brasil, 2017.

${ }^{2}$ Doutora e Mestre em Educação. Professora Associada da Universidade Federal do Rio grande - FURG. Líder do Grupo de Pesquisa Educação, Cultura, Ambiente e Filosofia - GEECAF/FURG. Bolsista Produtividade do CNPq. Rio Grande, Rio Grande do Sul, Brasil. paula.c.henning@ gmail.com.
} 
writing to weave seeking to launch a look at Environmental Education through in the media crossings that are part of the thesis corpus. The work searches for theoretical tools through Discourse Analysis, drawing inspiration from Michel Foucault, working specifically with discourse concept in the search of tensioning the conditions of possibilities of the discourses propagated. With the proposal in situ, compiled images linked to the environmental theme and, through this exercise, questions the expressive linkage of the area in relation to natural resources, such as air, water, flora, fauna or green. And, through images collected by different media crossings, with teaching experience in higher education and in consonance with the research developed, it is sought to create fissures of thought and reflection on what has been distributed in relation to the environmental theme, exercising a look who knows more attentive and less directed.

Keywords: Discourse Analysis; Environmental Education; Media; Green.

\section{Introdução}

O presente resumo provém de um doutoramento em Educação Ambiental na Universidade Federal de Rio Grande onde se analisa a proliferação de discursos relacionados ao "verde", porém, o desassossego provocado pela temática não é recente, fazendo um breve retrospecto, pode-se enxergar desde o período das graduações, experiência docente e o percurso que hoje conduziu ao doutorado, mais de quinze anos de estudos, pesquisas e inquietações. E, ao contrário do que possa aparecer, ao invés de encontrar respostas, encontrase ainda mais questionamentos e motivações para seguir em frente.

Com o aporte teórico de autores como Félix Guattari, Michel Foucault, dentre outros pares que estão sustentando as pesquisas, as orientações para o trabalho e o auxílio do Grupo de Pesquisa e Estudos em Educação, Cultura, Ambiente e Filosofia (GEECAF), que a tese vem sendo tecida e, em um Encontro Humanístico Multidisciplinar, compartilhamos um pouco do que vem sendo estudado.

Através das pesquisas, com as leituras, o olhar ficou muito sensível aos discursos e aos apelos ambientais. Estamos imersos em atravessamentos muitas vezes rasos e superficiais. Os discursos ambientais vinculados, muitas vezes, aos ambientes naturais, flora, fauna, água e poluição. Os comportamentos humanos em relação ao meio ambiente já são esperados de antemão: "temos que ser amigos da natureza", "tomar banho muito rápido", "reciclar" e "ser sustentável". Nesse emaranhado, percebeu-se o cerne do desassossego no reducionismo conceitual atrelado aos discursos ambientais. É muito verde! Muito apelo!

Diante disso, o presente trabalho, faz um recorte da tese com o desejo de problematizar verdades estabelecidas em relação as questões ambientais, pulverizadas em diferentes espaços e que fazem circular tantos discursos verdes. Será possível pensar diferente? 


\section{Tessitura}

Para a composição do trabalho, busca-se aproximação com a Análise do Discurso, buscando inspiração em Michel Foucault, operando especificamente com conceito de discurso na busca de tensionamento das condições de possibilidades dos discursos que são propagados. Para o filósofo, os discursos na maioria das vezes já são aceitos, aparecem como um bem finito, limitado, útil, com regras de aparecimento e condições de utilização (FOUCAULT, 2008, p. 136-137).

Os discursos são vistos como um conjunto de enunciados provenientes de um mesmo sistema de formação, através desses enunciados, pode-se obter um conjunto de condições de existência, além disso, um discurso não pode se encerrar nos limites materiais de uma obra, de um livro, é muito além do começo, do título e das linhas finais, está entremeado a um conjunto de referências a outros discursos e a outros autores (CASTRO, 2016, p. 117-118).

Os discursos estão pulverizados, atravessados nos modos de vida de diferentes maneiras. Diante das inúmeras informações repassadas e prontas, a mídia como disseminadora de "verdades", marketing, massivo estímulo ao consumo e, muitos discursos utilizando o verde como forte apelo, que se organiza o aporte para a sustentação do trabalho, busca de tensionamento das condições de possibilidades dos discursos propagados.

\section{Compondo a escrita}

Embora possamos perceber inúmeros discursos relacionados a temática ambiental atualmente e, mesmo que esses atravessamentos possam ser verificados por diferentes interstícios, não são recentes os estudos atribuídos a assuntos como natureza, meio ambiente ou educação ambiental. Os debates ambientais, principalmente atrelados à crise ambiental, vem sendo constantemente distribuídos desde os anos 70, em alguns momentos em menor ou maior intensidade, mas ainda assim, são presentes ao longo de décadas.

Em relação aos discursos ambientais Beck, Henning e Vieira (2014) comentam que a proliferação discursiva é percebida em massa, com inúmeros alertas para necessidade de se cuidar do Planeta e, de modo paradoxal, também incita ao consumo. Se antes, nos anos 70, Lutzenberger (1977) alertava para a necessidade de frear o consumo por estarmos acabando com o Planeta Terra; hoje, o que vemos é uma incitação permanente para consumirmos, mas pensando em um outro consumo, num consumo verde, numa onda verde que investe na subjetividade do indivíduo,

No final dos anos 80, Guattari (2015, p. 29) já comentava que o homem chamado de contemporâneo, estava enganchado em um mundo com precárias representações, tudo circula, 
mas parece permanecer tudo no mesmo lugar, subjetividade petrificada. Guimarães em 2011 alertava da sutil, lenta e incisiva instauração de processos de formação de novos sujeitos para habitar um mundo mais sustentável e "verde", imerso em mundo do mercado e do capital.

Atualmente os apelos são ainda mais perceptíveis, com a caminhada que hoje vive um doutorado, pode-se dizer que o olhar ficou muito mais atento e sensível aos discursos relacionados ao ambiente. E, nesse emaranhado discursivo fomos colhendo pistas para a escrita, sempre tomando o cuidado de ressaltar que em momento algum pretende-se elencar os discursos "verdadeiros ou falsos" ou então, "discursos científicos ou não", mas como diz Foucault (2015, p. 44), o que importa é verificar a produção desses discursos de verdade, que não são nem verdadeiros tampouco falsos. São discursos!

Os atravessamentos relacionados ao verde podem ser percebidos sem qualquer esforço aplicado, basta ficarmos atentos: folheando revistas, lendo o jornal, olhando alguns sites e até mesmo um momento de compras no supermercado. Aqui, chamando a atenção para um detalhe, ainda que esses aparatos midiáticos não tratem exclusivamente de temas relacionados ao meio ambiente e, assim como o momento de compras não seja apenas na sessão de produtos naturais: Os discursos estão por todos os lados! Estão pulverizados em nosso dia a dia, somos interpelados constantemente, mesmo que as vezes nem percebamos.

Além dos traspassamentos diários atrelados a matéria, o que pode-se verificar também, é que esses discursos vêm acompanhados concomitantemente a ideais de verdade, demonstrando e educando sobre as melhores maneiras de agir e se comportar perante ao que é distribuído.

Sampaio e Guimarães (2012, p. 402-403) ao analisarem a sustentabilidade, ressaltam que um "Um mundo mais verde e sustentável parece estar apenas começando, e para ele um novo sujeito é necessário." E, complementam sobre essa produção de sujeitos, que devem ser sensíveis a tantos apelos ligados a sustentabilidade e além disso, precisam estar dispostos a mudar os hábitos de vida em prol “dessa tal sustentabilidade”, que é tão distribuída, tão falada e pouco, ou quase nada pensada, afinal, ser verde é estar ligado ao seu tempo. Enquanto isso, o mercado se renova e se expande utilizando o subterfúgio verde como atrativo ao consumo.

Guimarães (2011) provoca a pensar:

Processos estes que não estão no horizonte de uma das configurações subjetivas mais atualizadas do contemporâneo. Essa que busca imprimir em nós, nos nossos desejos, nos nossos corpos, uma identidade "verde", ou seja, de um sujeito que interage "corretamente" com o planeta (sim, trata-se de uma identificação planetária e, portanto, não-localizada, não-regional, não-nacional, não-territorial, mas global). (grifos nossos). 
RELACult - Revista Latino-Americana de Estudos em Cultura e Sociedade

Revista Latinoamericana de Estudios en Cultura y Sociedad | Latin American Journal of Studies in Culture and Society V. 04, ed. especial, fev., 2018, artigo no 795 | relacult.claec.org | e-ISSN: 2525-7870

Aproveitando-se de Gilles Deleuze (2010, p. 124) que nos diz: "É preciso pegar as coisas para extrair dela as visibilidades. [...]é preciso rachar as palavras ou as frases delas extrair os enunciados", buscamos algumas visibilidades para compor o presente trabalho, para tanto, utilizamos algumas imagens que fazem parte do material empírico da pesquisa da tese, para ilustrar brevemente sobre a pulverização dos discursos ambientais:

Figura 1 - Composição de algumas imagens "verdes".

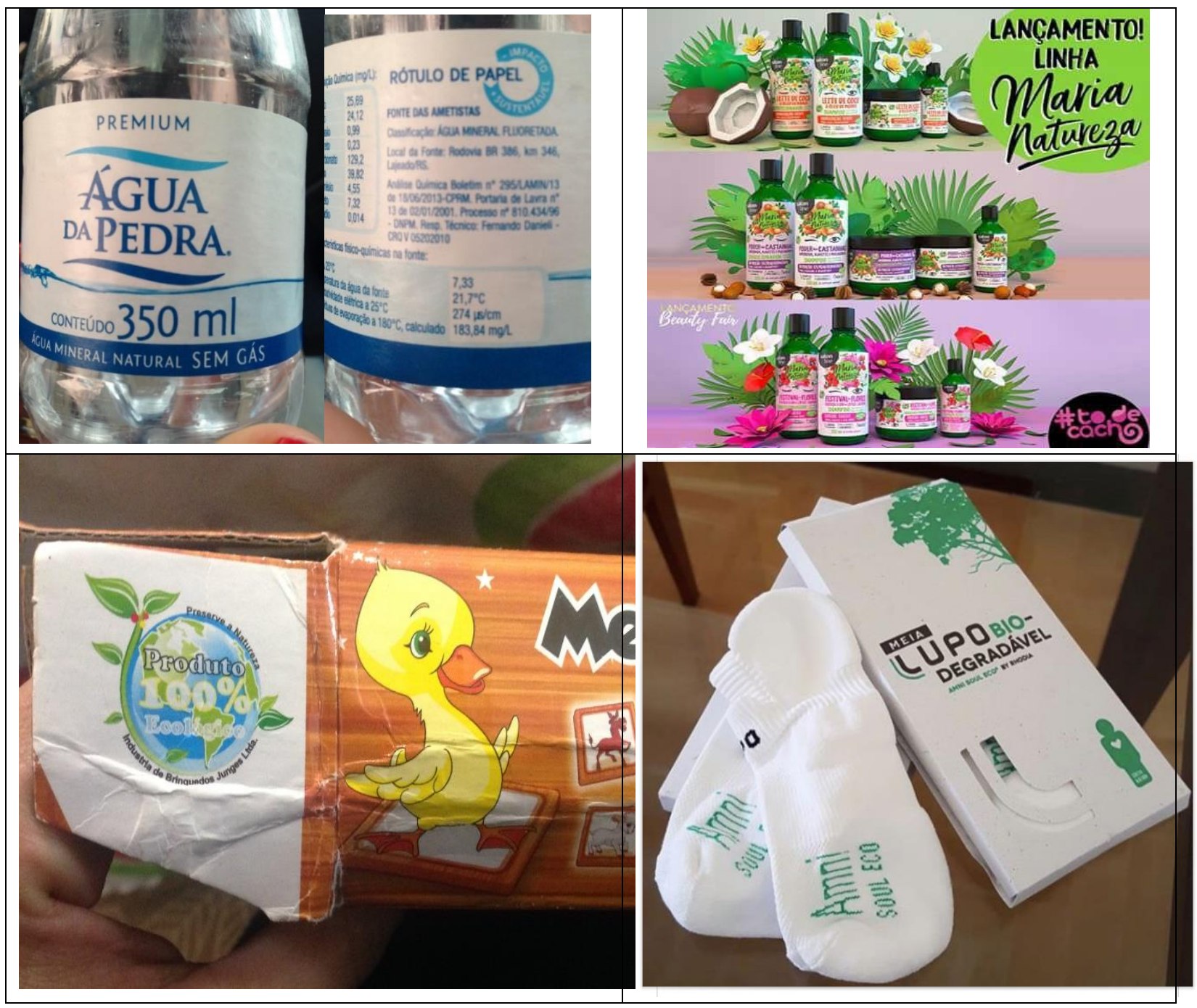

São apenas 4 imagens para ilustrar que o verde permeia diferentes interstícios e pode capturar diferentes consumidores: desde o que vai a um restaurante e consome uma água com apenas $350 \mathrm{ml}$ e um rótulo de papel denominado "impacto sustentável”, quem procura um brinquedo infantil que se declara $100 \%$ ecológico, na possibilidade de usar nos cabelos um produto que tem a "natureza" em seu nome e, focando também naqueles mais "em dia" com as questões ambientais com uma meia que, de acordo com o fabricante, se decompõe em 
poucos anos. Exemplifica-se não para apontar erros ou acertos, mas provocar que possamos pensar no quão esparramados podem ser os discursos relacionados ao verde.

Pode-se perceber que ao longo das últimas décadas uma significativa preocupação com as questões ambientais, seja através de conferências, leis, políticas públicas e trabalhos importantes. Porém, há um mercado que, aproveitando das tantas justificativas de preservação e proteção ambiental, utiliza o verde como incentivo a consumir determinados produtos ou serviços.

Com a pesquisa da tese, surpreende a quantidade e a diversidade de discursos permeando diferentes espaços, algumas empresas que mudaram as maneiras de produção e gestão para utilizar menos recursos, ou se adequaram buscando algumas certificações, mas também, existe parte do mercado em que sustentabilidade ambiental tem significado meramente simbólico. Nesse momento, não se trata de fazer juízo de valor e apontar discursos "verdadeiros" ou "falsos", mas a escrita almeja que possamos pensar sobre uma correnteza "Eco - lógica" que conduz, estimula e ensina a "sermos ecologicamente corretos" e, ainda, que se consuma produtos que convirjam nessa onda verde.

Será que uma imagem verdinha com uma árvore, ou então um desenho do planeta terra sorrindo podem trazer realmente credibilidade aos produtos que estamos consumindo? $\mathrm{E}$ aquela conhecida expressão "sustentável” pode nos dizer algo? O que é sustentável? O que é consumo consciente?

Discursos, muitos discursos que utilizam os apelos ambientais, e isso está tão distribuído que pouco se questiona, Foucault (2008, p. 24) diz que é preciso desalojar as formas e as obscuras forças que interligam os discursos dos homens, além disso, é preciso que nos inquietemos diante de certos recortes que já nos são familiares.

Além dos produtos, do mercado verde que vem crescendo, que nos "estimulam e ensinam a sermos ecologicamente corretos", lançamos nossos olhares também sobre a educação ambiental, sustentada também por esses discursos verdes, seus ideais, conceitos e suportes, mesmo sem querer, ainda que muitas vezes nem percebamos, já possui um conceito envolto em representações, atrelado a ideais de verdade: todos sabem algo, ou pensam que sabem alguma coisa também sobre a educação ambiental. Viu algo, leu alguma coisa...

Com essas confluências discursivas, com o que se tem verificado em diferentes mídias, nos parece haver conformismo com as informações distribuídas e também em relação aos comportamentos esperados. Desse modo, talvez seja pertinente problematizar e questionar sobre as intencionalidades das práticas educacionais denominadas "ambientais" assim como os propósitos de um mercado verde que cresce e se alastra. 


\section{Considerações}

Foi uma breve provocação, mas entende-se que a superfície de inscrição que trouxemos, de modo muito amplo, apresenta a sustentação antropocêntrica construída ao longo do tempo, um reducionismo conceitual entremeado às maneiras em que a natureza, meio ambiente e até mesmo a educação ambiental são muitas vezes apresentadas na contemporaneidade: Será mesmo que enquanto fizermos a nossa parte, sendo "ecologicamente corretos", consumindo produtos que utilizam as questões ambientais em suas embalagens e etiquetas, ou então agindo conforme os meios de comunicação orientam, ficará tudo bem?

Como nos tornamos o que somos hoje? Quanto do que julgamos ser opinião própria, ou conclusões obtidas através de nossos olhares, não são formações discursivas que vem sendo constantemente introjetadas em nossos modos de vida? Cuide da natureza! Pense verde! Seja sustentável! São representações, tantos discursos que são tão reproduzidos e pouco questionados.

Talvez os discursos estejam tão entranhados que não se pense a respeito do que está sendo descaradamente distribuído, nesse sentido, recordamos Deleuze que diz que pensar é ver, é falar, mas o olhar não pode permanecer apenas nas coisas, deve se elevar as "visibilidades", assim como a linguagem não fique atrelada as palavras, afinal, pensar é poder! (DELEUZE, 2010, p. 123).

As inquietações crescem e impulsionam a pesquisa, de tal modo, o trabalho, no tentame de lançar luz para discursos proliferantes na atualidade, convida, assim como Fisher (2002, p. 58), a deixar para trás o lago sereno das certezas e ir buscar ferramentas produtivas, para pensar de outra forma, procurando tencionar e quem sabe cotejar ideias menos seguras. Buscando uma leitura crítica do pensamento a partir da maneira como as coisas são ditas, compreendendo a problematização, não como um ajustamento de representações mas como um trabalho do pensamento (FOUCAULT, 2014, p. 227).

Desejando tecer outros modos de pensar as questões ambientais e fazer Educação Ambiental em tempos de "esverdeamento" dos sujeitos, aproveitamos Barchi (2013, p. 3266): mais importante que entrar em comportamentos paranoicos e totalizantes que dão a ecologia um status de eterna verdade, talvez possamos pensar em quebrar em milhões de pedaços e esquecer dos discursos enquanto unidade, talvez agindo com pensamento e prática em tentames de "descologizar" a ecologia e, confluindo a um "desverdeamento" dos sujeitos, possamos resistir a tanta cristalização e sedentarização das noções atribuídas ao ambiente. 
Não se busca encontrar respostas, tampouco soluções, busca-se provocar, resistir ou então, um convite a suspensão do hábito de cair em certezas. Se surtirá efeito, se irá mexer com alguém? Não importa nesse momento: Está en ti tomar (lo que te conviene) y dejar el resto, otro hará otro tanto, y poco a poco todo habrá encontrado su lugar. (...) elige y deja el resto sin declamar contra ese resto, (...). Piensa que gustará a otros...” (Guattari, 2015, p. 25).

Com Foucault, coloca-se um ponto, mas não um ponto final, um ponto para repousar o texto: "Existem momentos na vida onde a questão de saber se se pode pensar diferentemente do que se pensa, e perceber diferentemente do que se vê, é indispensável para continuar a olhar e a refletir" (FOUCAULT 1998, p. 13). O desejo é que os fios tecidos na composição desse exercício de escrita, possibilitem subversivos movimentos ao ato de pensar sobre os atravessamentos que interpelam o caminhar...

\section{Referências}

BARCHI, Rodrigo. A Educação ambiental como exercício de poder e resistência. REGET v. 17 n. 17, Dez. 2013, p. 3258- 3267.

BECK, D.; HENNING, P. E VIEIRA, V. Consumo e Cultura: modos de ser e viver a contemporaneidade. Educação, Sociedade e Culturas. N. 42, 2014, p.87-109. Disponível em www.fpce.up.pt/ciie/sites/default/files/ESC42_08DinahBeck.pdf. Acesso em 30 março 2017.

CASTRO, Edgardo. Vocabulário de Foucault. Um percurso pelos seus temas, conceitos e autores. $2^{\mathrm{a}}$ ed. Belo Horizonte. Editora autentica. 2016.

DELEUZE, Gilles. Conversações. Rio de Janeiro: Ed 34, 2010.

FISCHER, Rosa Maria Bueno. Verdades em suspenso: Foucault e os perigos a enfrentar. In.: Costa, Marisa Vorraber. (org). Caminhos investigativos II: outros modos de pensar e fazer pesquisa em educação. Rio de Janeiro: DP\&A, 2002.

FOUCAULT, Michel. Arqueologia do Saber. 7 ed. Rio de Janeiro: Forense Universitária, 2008.

Michel. Ditos e escritos, V: ética, sexualidade e política. 3 ed. Rio de Janeiro:

Forense Universitária, 2014.

, Michel. História da Sexualidade 2: o uso dos prazeres. Rio de Janeiro:

Edições Graal, 1998.

, Michel. Microfísica do Poder. São Paulo. Editora Paz e Terra. 2015.

GUATTARI, Félix. Qué es la ecosofia? textos presenteados y agenciados por Stéphane

Nadaud - $1^{a}$ ed. - Ciudad Autonoma de Buenos Aires: Cactus, 2015. 
GUIMARÃES, Leandro. Notas sobre o dispositivo da sustentabilidade e a formação de sujeitos "verdes". In.: Anais do $4^{\circ}$ SBECE, ULBRA, Canoas, 2011. P. 1-14.

LOVATO, Marcos Luiz. GREENWASHING NO BRASIL: quando a sustentabilidade ambiental se resume a um rótulo. Revista Eletrônica do Curso de Direito da UFSM, Santa Maria, RS, v. 8, p. 162-171, abr. 2013. ISSN 1981-3694. Disponível em:

<https://periodicos.ufsm.br/revistadireito/article/view/8257/4978>. Acesso em: 18 dez. 2017. doi: http://dx.doi.org/10.5902/198136948257.

LUTZENBERGER, José. Fim do futuro? manifesto ecológico brasileiro. Porto Alegre: Editora Movimento. 1977.

SAMPAIO, Shaula Maíra Vicentini, GUIMARÃES, Leandro Belinaso. O dispositivo da sustentabilidade: pedagogias no contemporâneo. .Revista Perspectiva Florianópolis, v. 30, n. 2, 395-409, maio/ago. 2012. 